\title{
Solution to wheat beer challenge
}

\section{Reinhard Meusinger ${ }^{1}$}

Published online: 3 January 2020

(C) Springer-Verlag GmbH Germany, part of Springer Nature 2019

Thank you for the very active participation in the wheat beer challeng (published in volume 411 issue 17). We are pleased to announce the lucky winner, who has been chosen at random:

Kevin Colizza, GlaxoSmithKline, Collegeville, PA, USA.

The award entitles the winner to select a Springer book of his choice up to a value of $€ 100,-$.

Our Congratulations!

"This article is the solution to the Analytical Challenge to be found at https://doi.org/10.1007/s00216-019-01854-7".

Compound Name: Ferulic acid

IUPAC name(E)-3-(4-hydroxy-3-methoxyphenyl)prop-2enoic acid
Molecular formulaC ${ }_{10} \mathrm{H}_{10} \mathrm{O}_{4}$

Molecular weight $194.18 \mathrm{~g} / \mathrm{mol}$

InChI 1 S/C 10H10O4/c1-14-9-6-7(2-4-8(9)11)3-510(12)13/h2-6,11H,1H3,(H,12,13)/b5-3+

CAS1135-24-6

The substance of the Wheat beer challenge is ferulic acid (Formula 1).<smiles>COc1cc(/C=C/C(=O)O)ccc1O</smiles>

Publisher's note Springer Nature remains neutral with regard to jurisdictional claims in published maps and institutional affiliations.
Reinhard Meusinger

meusi@nmr.chemie.tu-darmstadt.de

1 Institute of Organic Chemistry and Biochemistry, University of Technology Darmstadt, Alarich-Weiss-Str. 4,

D-64287 Darmstadt, Germany 